\title{
Seizure-Induced Periorbital Petechial Rash
}

\author{
Patrick Roth Dominik Zumsteg \\ Department of Neurology, University Hospital Zurich, Zurich, Switzerland
}

A 58-year-old man was admitted after a generalized tonic-clonic seizure. The neurological examination was normal, except for bilateral periorbital, enoral and superior thoracic petechiae, which had only occurred after the seizure. The blood pressure, CT scan of the brain and routine laboratory were unremarkable.

Seizure-related petechial rash is a rare finding that might be helpful for the diagnosis of an epileptic event in the absence of other objective signs $[1,2]$. It may occasionally show a predilection for the periorbital area, as in our case. The petechiae generally resolve spontaneously and do not need special treatment [3].
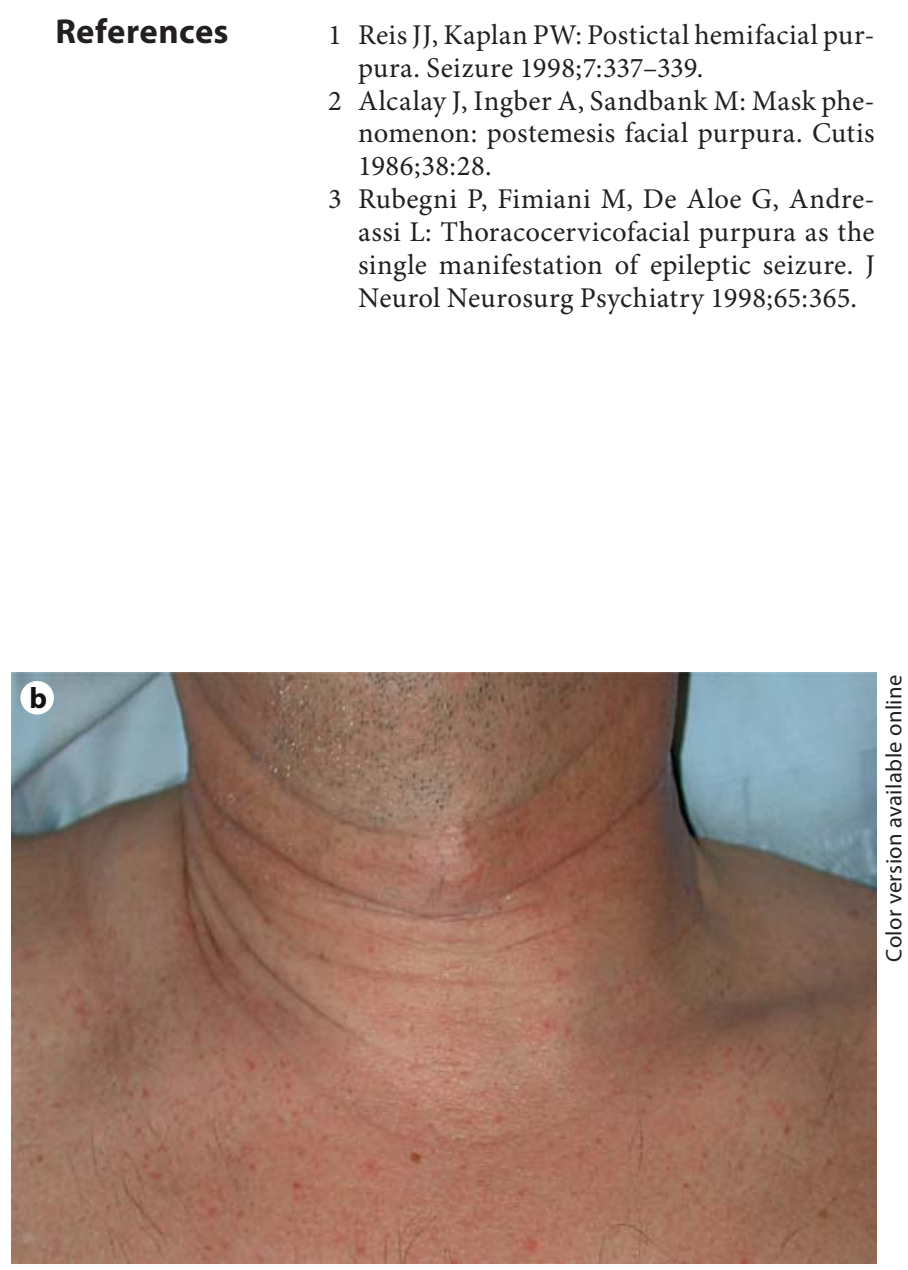

Fig. 1. Periorbital petechial rash (a) and symmetrically distributed petechiae at the superior thoracic aperture (b) that occurred after a generalized seizure.

\section{KARGER}

Fax +4161306 1234 E-Mail karger@karger.ch www.karger.com
(C) 2009 S. Karger AG, Basel $0014-3022 / 09 / 0615-0317 \$ 26.00 / 0$

Accessible online at:

www.karger.com/ene
Dr. Patrick Roth

Department of Neurology, University Hospital Zurich

Frauenklinikstrasse 26

$\mathrm{CH}-8091$ Zurich (Switzerland)

Tel. +41 44255 5511, Fax +41 44255 4380, E-Mail patrick.roth@usz.ch 